\title{
Arsenic trioxide inhibits breast cancer cell growth via microRNA-328/hERG pathway in MCF-7 cells
}

\author{
YING WANG $^{1}$, LEQIU WANG ${ }^{2}$, CHANGHAO YIN ${ }^{3}$, BAIZHU AN ${ }^{4}$, \\ YANKUN HAO ${ }^{1}$, TAO WEI ${ }^{1}, \mathrm{LI} \mathrm{LI}^{1}$ and GAOCHEN SONG ${ }^{1}$ \\ ${ }^{1}$ Medical Functional Laboratory, Mudanjiang Medical University; Departments of ${ }^{2}$ Otolaryngology and ${ }^{3}$ Neurology, \\ Hongqi Hospital of Mudanjiang Medical University; ${ }^{4}$ Department of Anatomy, Mudanjiang Medical University, \\ Mudanjiang, Heilongjiang 157011, P.R. China
}

Received May 27, 2014; Accepted March 3, 2015

DOI: $10.3892 / \mathrm{mmr} .2015 .3558$

\begin{abstract}
Arsenic trioxide $\left(\mathrm{As}_{2} \mathrm{O}_{3}\right)$ has been widely used in the treatment of acute promyelocytic leukemia and has been observed to exhibit therapeutic effects in various types of solid tumor. In a previous study by this group, it was shown that $\mathrm{As}_{2} \mathrm{O}_{3}$ induces the apoptosis of MCF-7 breast cancer cells through inhibition of the human ether-à-go-go-related gene (hERG) channel. The present study was designed to further investigate the effect of $\mathrm{As}_{2} \mathrm{O}_{3}$ on breast cancer cells and to examine the mechanism underlying the regulation of hERG expression. The present study confirmed that $\mathrm{As}_{2} \mathrm{O}_{3}$ inhibited tumor growth in vivo, following MCF-7 cell implantation into nude mice. Using computational prediction, it was identified that microRNA (miR)-328 had a binding site in the 3'-untranslated region of hERG mRNA. A luciferase activity assay demonstrated that hERG is a target gene of miR-328. Further investigation using western blot analysis and reverse transcription-quantitative polymerase chain reaction revealed that $\mathrm{As}_{2} \mathrm{O}_{3}$ downregulated $\mathrm{hERG}$ expression via upregulation of miR-328 expression in MCF-7 cells. In conclusion, $\mathrm{As}_{2} \mathrm{O}_{3}$ was observed to inhibit breast cancer cell growth, at least in part, through the miR-328/hERG pathway.
\end{abstract}

\section{Introduction}

Arsenic trioxide $\left(\mathrm{As}_{2} \mathrm{O}_{3}\right)$ has been used medicinally for $>2,400$ years for conditions ranging from infectious diseases to cancer (1). It was not until 1970, that researchers at Harbin Medical University observed its ability to treat acute promyelocytic leukemia $(2,3) . \mathrm{As}_{2} \mathrm{O}_{3}$ has also been demonstrated to exert inhibitory effects in various types of cancer. In MGC-803

Correspondence to: Professor Gaochen Song, Medical Functional Laboratory, Mudanjiang Medical University, 3 Tongxiang Street, Mudanjiang, Heilongjiang 157011, P.R. China

E-mail: 179057738@qq.com

Key words: arsenic trioxide, human ether-à-go-go-related gene, microRNA-328, MCF-7 human gastric cancer cells, $\mathrm{As}_{2} \mathrm{O}_{3}$ was shown to inhibit cell growth and to induce cell apoptosis (4). Similar findings were observed in esophageal carcinoma (5), neuroblastoma (6), prostate and ovarian carcinoma (7), and breast cancer (8) cells. Several mechanism of action involved in the $\mathrm{As}_{2} \mathrm{O}_{3}$-induced apoptosis of cancer cells have been identified $(8,9)$.

The human ether-à-go-go-related gene (hERG) is expressed in a number of tumor cell lines of various histogenetic origins, although is not present in the corresponding healthy cells, which indicates an association between hERG expression and the development of cancer (10-12). In a previous study by this group, it was identified that $\mathrm{As}_{2} \mathrm{O}_{3}$ induces the apoptosis of MCF-7 breast cancer cells via inhibition of hERG channels (13). To date, the molecular mechanisms underlying the regulation of hERG expression in breast cancer cells remain to be elucidated.

MicroRNAs (miRNAs/miRs) are a class of evolutionarily conserved, endogenous non-coding RNAs of $\sim 22$ nucleotides in length. They regulate gene expression at the post-transcriptional level by binding to the 3'-untranslated region (UTR) of the target mRNA. Altered expression of miRNAs has been demonstrated to be involved in cancer development and progression. To date, a number of downregulated miRNAs identified in breast cancer have also been shown to be associated with apoptosis $(14,15)$ and metastasis $(16,17)$.

Through computational prediction, it was shown that miR-328 may target the 3'-UTR of hERG mRNA. These findings prompted the hypothesis that $\mathrm{As}_{2} \mathrm{O}_{3}$ may inhibit breast cancer cell growth via the miR-328/hERG pathway. The present study was conducted to assess this hypothesis.

\section{Materials and methods}

Materials. $\mathrm{As}_{2} \mathrm{O}_{3}$ was obtained from Jiangsu Yida Chemical Co., Ltd. (Jiangyin, China) and was diluted with phosphate-buffered saline (PBS) to prepare a $10 \mathrm{mM}$ stock solution, which was stored at $4^{\circ} \mathrm{C}$ in darkness.

Cell line and cell culture. The MCF-7 human breast cancer cell line was obtained from the American Type Culture Collection (Manassas, VA, USA). The cells were maintained in RPMI-1640 (Hyclone, Logan, UT, USA) supplemented with 
$10 \%$ fetal bovine serum (Hyclone) in a humidified atmosphere with $5 \% \mathrm{CO}_{2}$ at $37^{\circ} \mathrm{C}$.

In vivo tumor xenograft model. A total of 30 female BALB/c nude mice (nu/nu, 8 weeks old) were obtained from the Third Affiliated Hospital of Harbin Medical University (Harbin, China). The MCF-7 cells were inoculated subcutaneously into the flank of each mouse $\left(5 \times 10^{6}\right.$ cells in $200 \mu$ PBS $)(18)$. At 2 weeks following tumor implantation, the mice were randomly divided into three groups each containing 10 mice. The $\mathrm{As}_{2} \mathrm{O}_{3}$-treated groups were injected daily with 4 or $8 \mathrm{mg} / \mathrm{kg}$ of $\mathrm{As}_{2} \mathrm{O}_{3}$ for 7 days The control group was administered with an equal volume of saline. Tumor size was measured using calipers and the volume was calculated according to the formula: $V=L x W^{2} / 2$, where $L$ and $W$ represent the length and width, respectively. The mice were weighed twice a week. Any investigations using the mice were performed in compliance with the guidelines of the Institute for Laboratory Animal Research, Mudangjiang Medical University.

Luciferase assay. The 3'-UTR of the hERG mRNA was obtained by polymerase chain reaction (PCR) amplification, and the PCR product was inserted into the firefly luciferase gene reporter construct (pMIR-REPORTTM; Ambion Life Technologies, Austin, TX, USA) as described previously (19). Mutation of the hERG sequence was created using a Quick Change Site-Directed Mutagenesis kit (Stratagene, Santa Clara, CA, USA). The miR-328 precursor (pre-miR-328) and a control precursor (scramble) were purchased from Ambion Life Technologies.

For the luciferase assay, HEK-293 cells were co-transfected with wild-type or mutant hERG 3'-UTR luciferase reporter plasmid, and pS-Neg or miR-328 expression plasmid, using Lipofectamine ${ }^{\circledR} 2000$ (Invitrogen Life Technologies, Carlsbad, CA, USA). The luciferase activity was determined using a dual luciferase reporter assay system (Promega Corporation, Madison, WI, USA) at $48 \mathrm{~h}$ following transfection, according to the manufacturer's instructions.

Reverse transcription-quantitative PCR (RT-qPCR). Total RNA was extracted from MCF-7 cells using TRIzol ${ }^{\circledR}$ reagent (Invitrogen Life Technologies) according to the manufacturer's instructions. miR-328 levels were quantified using the mirVana qRT-PCR miRNA detection kit (Ambion Life Technologies), according to the manufacturer's instructions. Variations in the expression of miR-328 between different RNA samples were calculated following normalization to levels of U6.

Western blot analysis. Western blot analysis was conducted as described previously (20). The cells were washed with cold PBS and lysed in lysis buffer [western blot lysate: protease inhibitor cocktail (100:1); Beyotime Institute of Biotechnology, Haimen, China]. The concentration of proteins was determined using a bicinchoninic protein assay kit (Beyotime Institute of Biotechnology). The samples were electrophoresed using $10 \%$ SDS-PAGE. Following electrophoresis, the gels were transferred onto nitrocellulose membranes via electroblotting and blocked in 5\% non-fat milk in PBS for $2 \mathrm{~h}$. Subsequently, the membrane was incubated with polyclonal rabbit anti-hERG antibody (cat.no. sc-20130; 1:200 dilution; Santa Cruz
Biotechnology, Inc., Santa Cruz, CA, USA) and polyclonal rabbit anti-GAPDH antibody (cat. no. sc-25778; 1:1,000 dilution; Santa Cruz Biotechnology, Inc.) in PBS and incubated at $4^{\circ} \mathrm{C}$ overnight. The following day, the membranes were washed three times with PBS for $5 \mathrm{~min}$ at room temperature and subsequently incubated with HRP-conjugated anti-rabbit IgG polyclonal secondary antibodies (1:10,000 dilution; cat. no. sc-2357, Santa Cruz Biotechnology, Inc.) for $2 \mathrm{~h}$ at room temperature. The Odyssey infrared fluorescence scanning system (LI-COR Biosciences, Lincoln, NE, USA) was used to detect protein bands. The intensity of the bands was determined by densitometry using Odyssey version 1.2 software (LI-COR Biosciences, Lincoln, NE, USA).

Statistical analysis. All data are presented as the mean \pm standard deviation for three repeated experiments. Student's t-test and SPSS 16.0 (SPSS, Inc., Chicago, IL, USA) were used for statistical analysis. $\mathrm{P}<0.05$ was considered to indicate a statistically significant difference.

\section{Results}

$\mathrm{As}_{2} \mathrm{O}_{3}$ inhibits tumor growth in MCF-7-inoculated nude mice. In order to examine the effect of $\mathrm{As}_{2} \mathrm{O}_{3}$ on breast cancer cells in vivo, human tumor xenografts were investigated in nude mice. The size of the tumor was measured, as shown in Fig. 1, in mice treated with 4 and $8 \mathrm{mg} / \mathrm{kg}$, and $\mathrm{As}_{2} \mathrm{O}_{3}$-treated mice exhibited significant tumor growth retardation. The tumor volume of the non-treated mice increased between $1.19 \pm 0.31$ and $3.18 \pm 0.67 \mathrm{~cm}^{3}$, in comparison with mice treated with $4 \mathrm{mg} / \mathrm{kg} \mathrm{As}_{2} \mathrm{O}_{3}$, which exhibited significant growth retardation, with tumor growth of between $0.74 \pm 0.30$ and $0.97 \pm 0.57 \mathrm{~cm}^{3}$. Notably, for the groups treated with $8 \mathrm{mg} / \mathrm{kg} \mathrm{As} \mathrm{O}_{3}$, the tumor volume decreased between $1.44 \pm 0.55$ and $1.02 \pm 0.42 \mathrm{~cm}^{3}$. Regarding side effects of $\mathrm{As}_{2} \mathrm{O}_{3}$, no signs of toxicity were observed between the different groups, as judged at autopsy (data not shown). The present results indicated that $\mathrm{As}_{2} \mathrm{O}_{3}$ is effective in inhibiting tumor growth in MCF-7-inoculated nude mice.

$\mathrm{As}_{2} \mathrm{O}_{3}$ upregulates expression of miR-328 and downregulates expression of $h E R G$. In order to further examine the mechanism underlying the regulation of hERG expression, the 3'-UTR of hERG was analyzed using the online databases, TargetScan Human version 6.2 (http://www.targetscan.org) and miRBase version 20.0 (http://www.mirbase.org), to identify potential interacting miRNAs. miR-133 and miR-328 were selected as likely interactors. Of the two selected miRNAs, miR-133 has been previously described as a muscle-specific miRNA, which has been investigated primarily with regard to the heart $(21,22)$. Therefore, miR-328, a known tumor suppressor, was selected for further analysis.

Initially, the expression of miR-328 and hERG was detected in MCF-7 cells. The level of miR-328 was determined using RT-qPCR after MCF-7 cells had been treated with $8 \mu \mathrm{M} \mathrm{As}{ }_{2} \mathrm{O}_{3}$ for $48 \mathrm{~h}$. As shown in Fig. 2A, the expression of miR-328 in the treated cells increased by $56 \pm 0.34 \%$ compared with the level in non-treated cells. Subsequently, the level of hERG was determined using western blot analysis, following treatment of MCF-7 cells with $8 \mu \mathrm{M} \mathrm{As}_{2} \mathrm{O}_{3}$ for the same time 


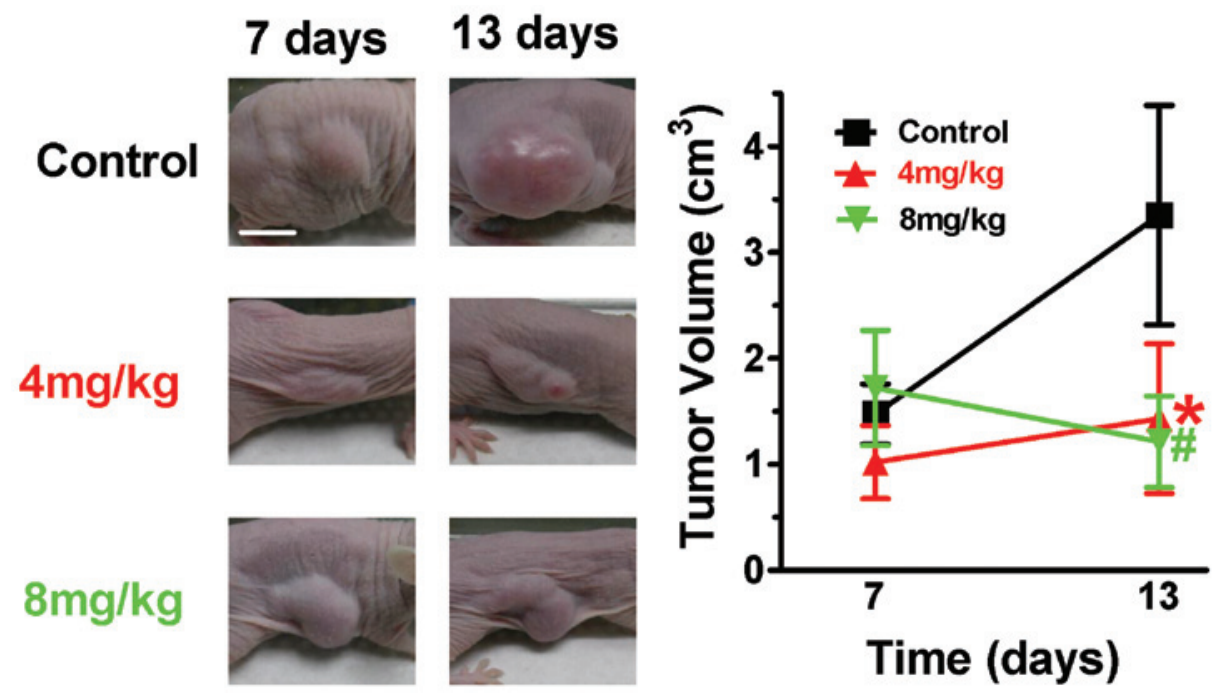

Figure 1. $\mathrm{As}_{2} \mathrm{O}_{3}$ inhibits tumor growth in nude mice with tumor xenografts. Left panel, images of tumor-bearing nude mice with or without $\mathrm{As}_{2} \mathrm{O}_{3}$ treatment at 7 and 13 days following initial inoculation. Scale bar $=1 \mathrm{~cm}$. Right panel, tumor volume of nude mice with tumor xenografts. Following tumor inoculation, nude mice were administered daily with saline and 4 or $8 \mathrm{mg} / \mathrm{kg} \mathrm{As}_{2} \mathrm{O}_{3}$ over 7 days ( $\mathrm{n}=5$ mice for each group). Tumor volume was measured and plotted in the graph. ${ }^{*} \mathrm{P}<0.05$, versus control and ${ }^{\#} \mathrm{P}<0.01$, versus control.

A

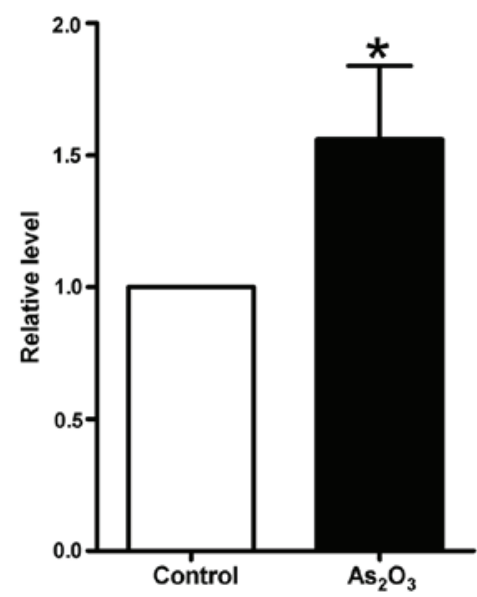

B
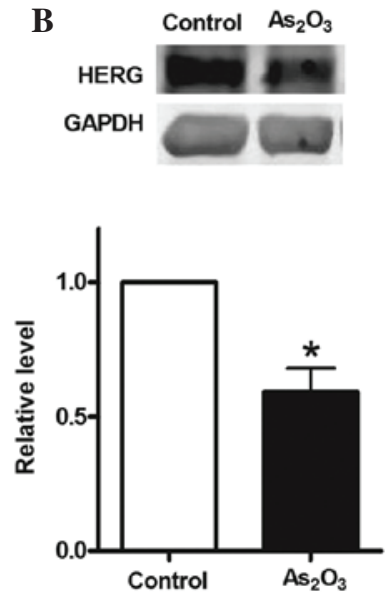

Figure 2. Expression of miR-328 and hERG in $\mathrm{As}_{2} \mathrm{O}_{3}$-treated MCF-7 human breast cancer cells. (A) $\mathrm{As}_{2} \mathrm{O}_{3}$ upregulates miR-328 in MCF-7 cells. Total RNA extracted from MCF-7 cells was used to analyze miR-328 expression by reverse transcription-quantitative polymerase chain reaction. (B) $\mathrm{As}_{2} \mathrm{O}_{3}$ downregulates hERG in MCF-7 cells. Whole cellular lysates extracted from MCF-7 cells were used to analyze hERG protein expression by western blot analysis. Results are representative of three separate experiments. "P<0.05, versus control. hERG, human ether-à-go-go-related gene; miR, microRNA; $\mathrm{As}_{2} \mathrm{O}_{3}$, arsenic trioxide.

period. As shown in Fig. 2B, the expression of hERG in the treated group decreased by $41 \pm 0.11 \%$ compared with that in the control group. It was therefore hypothesized that there is an inverse correlation between miR-328 and hERG protein expression levels.

$h E R G$ is a direct target of miR-328. It was hypothesized that miR-328 interacts directly with the 3'-UTR of hERG mRNA to suppress hERG expression. In order to assess this hypothesis, the ability of miR-328 to regulate the 3'-UTR of hERG was evaluated using luciferase reporter assays. The region from nucleotide +77 to nucleotide +83 of the $\mathrm{hERG}$ sequence (NM-001204798) was cloned downstream of a reporter luciferase gene (Fig. 3A).

HEK-293 cells were co-transfected with reporter plasmid and pre-miR-328/scramble miR. As a result, co-transfection of synthetic miR-328 and hERG-wildtype reduced the luciferase activity by $\sim 46 \%$, which was a significant difference compared with the scramble group. However, co-transfection of miR-328 in cells transfected with hERG-mutant did not significantly affect luciferase activity (Fig. 3B).

The most straightforward prediction from the luciferase reporter assay would be that ectopic expression of miR-328 should reduce hERG protein levels in MCF-7 cells. In order to further investigate the interaction between miR-328 and hERG, MCF-7 cells were transfected with pre-miR-328. Following pre-miR-328 transfection in MCF-7 cells (Fig. 3C), western blotting was conducted to measure the level of hERG protein. It was identified that the expression of hERG protein was downregulated by $\sim 37 \%$ in pre-miR-328-treated MCF-7 cells. These data suggested that miR-328 directly recognizes the 3'-UTR of hERG mRNA and inhibits hERG translation. 
A

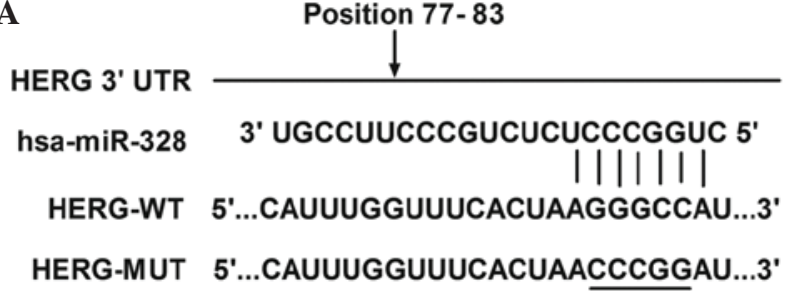

B

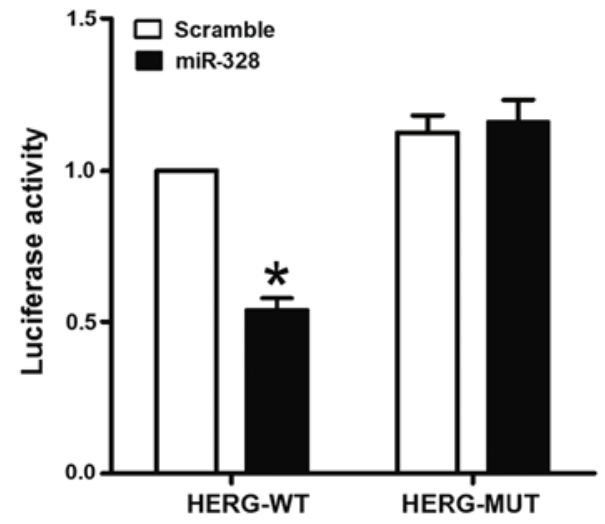

C
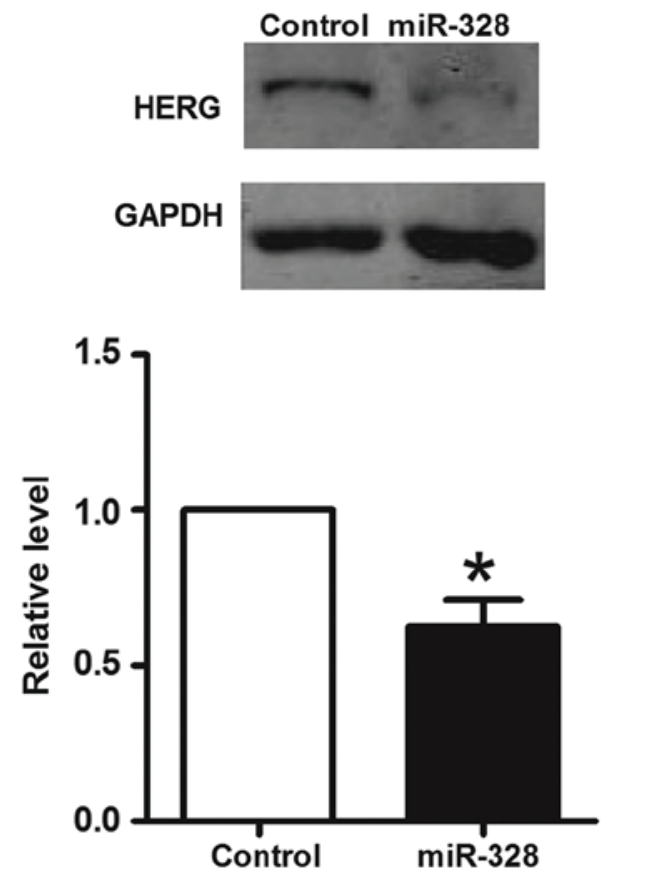

Figure 3. hERG is experimentally validated as a direct target of miR-328 in breast cancer cells. (A) Sequence of the miR-328 binding sites within the hERG 3'-UTR and a schematic diagram of the reporter constructs demonstrating the entire hERG 3'-UTR sequence (hERG-WT) and the mutated hERG 3'-UTR sequence (hERG-MUT; the mutant nucleotides of the miR-328 binding site are underlined). (B) Luciferase activity of the hERG-WT reporter and the hERG-MUT reporter in the presence of $10 \mathrm{nmol} / 1$ pre-miR-328 or scramble. (C) Effect of miR-328 on the expression of hERG protein in MCF-7 cells. Quantitative analysis was performed with GAPDH as an internal control. " $\mathrm{P}<0.01$, versus control. hERG, human ether-à-go-go-related gene; miR, microRNA; $\mathrm{As}_{2} \mathrm{O}_{3}$, arsenic trioxide; UTR, untranslated region; WT, wildtype; MUT, mutant; hsa, human miRNA.

\section{Discussion}

Breast cancer is the most common type of cancer and is the leading cause of cancer-associated mortality in females, accounting for $25 \%$ of new cancer cases and $15 \%$ of the total global cancer-associated mortality in 2012 (23). Although important advances have been made in the early detection, prevention and treatment of breast cancer, chemotherapy remains the primary method of treatment, which leads to cumulative toxicity and has additional tolerability problems (24). An improved knowledge of tumor biology is providing the opportunity to treat breast cancer with a new class of anticancer drugs.

hERG is overexpressed in numerous types of cancer in humans, including endometrial cancer, leukemia, melanoma and neuroblastoma, and inhibition of the hERG channel may reduce cancer cell growth and proliferation (25-27). Furthermore, this group has recently demonstrated that $\mathrm{As}_{2} \mathrm{O}_{3}$ induces the apoptosis of MCF-7 cells through inhibition of the hERG channel (13). However, the mechanisms that regulate the expression of the hERG channel remain to be elucidated. Therefore, an objective of the present study was to identify potential miRNAs that are able to regulate hERG expression in human breast cancer cells.

The studies discussed thus far on miRNAs, reflect their ability to act as onco-miRNAs or oncosuppressor-miRNAs, by favoring or inhibiting tumor progression. In the present study, it was identified that in MCF-7 breast cancer cells, miR-328 is able to target the 3'UTR of hERG and to decrease its level of expression, thus suggesting that by maintaining hERG expression at a low level, the activity of miR-328 may contribute to tumor suppression.

In previous years, a number of miRNAs have been implicated in the development of human breast cancer. Iorio et al (28) first demonstrated miRNA dysregulation in human breast cancer. The authors found that miR-10b, miR-125b and miR-145 were downregulated, while miR-21 and miR-155 were upregulated, suggesting that they may act as potential tumor suppressor genes or oncogenes. Subsequently, additional functional studies were conducted in order to identify specific miRNAs involved in breast cancer. Wang et al (29) observed that miR-145 was downregulated in MCF-7 cells, and overexpression of miR-145 suppressed MCF-7 cell growth and induced apoptosis. Kong et al (30) demonstrated that miR-155 induces cell survival by targeting forkhead box O3a in breast cancer cells. Song et al (31) revealed that miR-21 negatively regulates TIMP metallopeptidase inhibitor 3 expression in breast cancer cells and promotes breast cancer invasion in multiple cell lines in vitro.

miR-328 expression in human cancer has not been extensively investigated thus far. Previously, miR-328 has been shown to be expressed in the small intestine and liver (32). Furthermore, it appears to be downregulated in high-grade gliomas (33) and a previous study demonstrated that it was also downregulated in the human colorectal cancer cell lines, HT29, HCT116 and HCT8 (32). In 5-Fluorouracil-treated MCF-7 cells, the expression of miR-328 increased in comparison with control cells (34). Similar results were observed in the present study, where miR-328 expression was upregulated in $\mathrm{As}_{2} \mathrm{O}_{3}$-treated MCF-7 cells.

Notably, miR-328 has been demonstrated to have dual actions in the regulation of cell functions, through base pairing with mRNA targets and via a decoy activity that interferes with the function of regulatory proteins (35). A 
recent study demonstrated that miR-328 was able to target the 3'UTR of the breast cancer resistance protein, ATP-binding cassette sub-family G member 2 (ABCG2) and, consequently, repress $\mathrm{ABCG} 2$ protein expression and increase cancer cell sensitivity to drug treatment (36). miR-328 is also closely associated with cell cycle progression. It may increase proliferation of HeLa and SKBr3 cells, via downregulation of protein tyrosine phosphatase, receptor type, $\mathrm{J}$ expression (37). Furthermore, ectopic miR-328 expression in glioblastoma cells may significantly suppress cell proliferation (33). Thus, the role of miR-328 in a appears to be dependent on the particular cell type involved.

The present data revealed that miR-328 expression is inversely correlated with hERG expression in MCF-7 breast cancer cells. However, the mechanisms underlying the regulation of miR-328 in human cancer remain to be elucidated and therefore require further investigation.

In conclusion, the results of the present study demonstrated a novel mechanism for the regulation of hERG expression by miR-328 in breast cancer cells, indicating that miR-328-hERG signaling mediated by $\mathrm{As}_{2} \mathrm{O}_{3}$ may represent a novel therapeutic target for breast cancer.

\section{Acknowledgements}

The present study was supported by the Scientific Research Fund of Heilongjiang Provincial Health Department (grant no. 2011-323), the Scientific Research Fund of Mudanjiang Medical University (grant no. 2011-07), the Fund for Emergency Management of the National Natural Science Foundation of China (grant no. 81441113) and the Youth Science and Technology Project of Heilongjiang Traditional Chinese Medicine (grant no. ZQG-056).

\section{References}

1. Klaassen CD: Heavy metals and heavy-metal antagonists. In: The Pharmacological Basis of Therapeutics. Gilman (ed.) McGraw-Hill, New York, NY, pp 649-1672, 1996.

2. Cyranoski D: Arsenic patent keeps drug for rare cancer out of reach of many. Nat Med 13: 1005, 2007.

3. Sun HD, Ma L and Hu XC and Zhang TD: Ai-Lin I treated 32 cases of acute promyelocytic leukemia. Chin J Integr Chin W Med 12: 170-171, 1992.

4. Zhang TC, Cao EH, Li JF, Ma W and Qin JF: Induction of apoptosis and inhibition of human gastric cancer MGC-803 cell growth by arsenic trioxide. Eur J Cancer 35: 1258-1263, 1999.

5. Shen ZY, Shen J, Cai WJ, Hong C and Zheng MH: The alteration of mitochondria is an early event of arsenic trioxide induced apoptosis in esophageal carcinoma cells. Int J Mol Med 5: $155-158,2000$.

6. Akao Y, Nakagawa Y and Akiyama K: Arsenic trioxide induces apoptosis in neuroblastoma cell lines through the activation of caspase 3 in vitro. FEBS Lett 455: 59-62, 1999.

7. Uslu R, Sanli UA, Sezgin C, Karabulut B, Terzioglu E, Omay SB and Goker E: Arsenic trioxide-mediated cytotoxicity and apoptosis in prostate and ovarian carcinoma cell lines. Clin Cancer Res 6: 4957-4964, 2000.

8. Chow SK, Chan JY and Fung KP: Inhibition of cell proliferation and the action mechanisms of arsenic trioxide (As2O3) on human breast cancer cells. J Cell Biochem 93: 173-187, 2004.

9. Ye J, Li A, Liu Q, Wang X and Zhou J: Inhibition of mitogen-activated protein kinase kinase enhances apoptosis induced by arsenic trioxide in human breast cancer MCF-7 cells Clin Exp Pharmacol Physiol 32: 1042-1048, 2005.

10. Crociani O, Guasti L, Balzi M, et al: Cell cycle-dependent expression of HERG1 and HERG1B isoforms in tumor cells J Biol Chem 278: 2947-2955, 2003.
11. Guasti L, Crociani O, Redaelli E, Pillozzi S, Polvani S, Masselli M, Mello T, Galli A, Amedei A, Wymore RS, et al: Identification of a posttranslational mechanism for the regulation of hERG1 K+ channel expression and hERG1 current density in tumor cells. Mol Cell Biol 28: 5043-5060, 2008.

12. Arcangeli A: Expression and role of hERG channels in cancer cells. Novartis Found Symp 266: 225-232, 2005.

13. Wang Y, Zhang Y, Yang L, Cai B, Li J, Zhou Y, Yin L, Yang L, Yang $\mathrm{BF}$ and $\mathrm{Lu} \mathrm{YJ}$ : Arsenic trioxide induces the apoptosis of human breast cancer MCF-7 cells through activation of caspase-3 and inhibition of HERG channels. Exp Ther Med 2: 481-486, 2011.

14. Wang S, Bian C, Yang Z, Bo Y, Li J, Zeng L, Zhou H and Zhao RC: miR-145 inhibits breast cancer cell growth through RTKN. Int J Oncol 34: 1461-1466, 2009.

15. Kato M, Paranjape T, Müller RU, Nallur S, Gillespie E, Keane K, Esquela-Kerscher A, Weidhaas JB and Slack FJ: The mir-34 microRNA is required for the DNA damage response in vivo in C. elegans and in vitro in human breast cancer cells. Oncogene 28: 2419-2424, 2009.

16. Gregory PA, Bert AG, Paterson EL, Barry SC, Tsykin A, Farshid G, Vadas MA, Khew-Goodall Y and Goodall GJ: The miR-200 family and miR-205 regulate epithelial to mesenchymal transition by targeting ZEB1 and SIP1. Nat Cell Biol 10: 593-601, 2008.

17. Valastyan S, Reinhardt F, Benaich N, Calogrias D, Szász AM, Wang ZC, Brock JE, Richardson AL and Weinberg RA: A pleiotropically acting microRNA, miR-31, inhibits breast cancer metastasis. Cell 137: 1032-1046, 2009.

18. Wu G, Qiu XL, Zhou L, Zhu J, Chamberlin R, Lau J, Chen PL and Lee WH: Small molecule targeting the Hec1/Nek2 mitotic pathway suppresses tumor cell growth in culture and in animal. Cancer Res 68: 8393-8399, 2008.

19. Yang B, Lin H, Xiao J, Lu Y, Luo X, Li B, Zhang Y, Xu C, Bai Y, Wang $\mathrm{H}$, et al: The muscle-specific microRNA miR-1 regulates cardiac arrhythmogenic potential by targeting GJA1 and KCNJ2 . Nat Med 13: 486-491, 2007.

20. Lu Y, Zhang Y, Wang N, Pan Z, Gao X, Zhang F, Zhang Y, Shan H, Luo X, Bai Y, et al: MicroRNA-328 contributes to adverse electrical remodeling in atrial fibrillation. Circulation 122: 2378-2387, 2010.

21. Shan H, Zhang Y, Lu Y, Zhang Y, Pan Z, Cai B, Wang N, Li X, Feng T, Hong Y, et al: Downregulation of miR-133 and miR-590 contributes to nicotine-induced atrial remodelling in canines. Cardiovasc Res 83: 465-472, 2009.

22. Cai B, Pan Z and Lu Y: The roles of microRNAs in heart diseases: A novel important regulator. Curr Med Chem 17: 407-411, 2010

23. Torre LA, Bray F, Siegel RL, Ferlay J, Lortet-Tieulent J and Jemal A: Global cancer statistics, 2012. CA Cancer J Clin: Feb 4, 2015 (Epub ahead of print).

24. Vahdat LT, Pruitt B, Fabian CJ, Rivera RR, Smith DA, Tan-Chiu E, Wright J, Tan AR, Dacosta NA, Chuang E, et al: Phase II study of eribulin mesylate, a halichondrin B analog, in patients with metastatic breast cancer previously treated with an anthracycline and a taxane. J Clin Oncol 27: 2954-2961, 2009.

25. Li H, Liu L, Guo L, et al: HERG K+ channel expression in CD34+/CD38-/CD123(high) cells and primary leukemia cells and analysis of its regulation in leukemia cells. Int J Hematol 87: 387-392, 2008

26. Afrasiabi E, Hietamäki M, Viitanen T, Sukumaran P, Bergelin N and Törnquist K: Expression and significance of HERG (KCNH2) potassium channels in the regulation of MDA-MB-435S melanoma cell proliferation and migration. Cell Signal 22: 57-64, 2010.

27. Zhao J, Wei XL, Jia YS and Zheng JQ: Silencing of herg gene by shRNA inhibits SH-SY5Y cell growth in vitro and in vivo. Eur J Pharmacol 579: 50-57, 2008.

28. Iorio MV, Ferracin M, Liu CG, Veronese A, Spizzo R, Sabbioni S, Magri E, Pedriali M, Fabbri M, Campiglio M, et al: MicroRNA gene expression deregulation in human breast cancer. Cancer Res 65: 7065-7070, 2005.

29. Wang S, Bian C, Yang Z, Bo Y, Li J, Zeng L, Zhou H and Zhao RC: miR-145 inhibits breast cancer cell growth through RTKN. Int J Oncol 34: 1461-1466, 2009.

30. Kong W, He L, Coppola M, Guo J, Esposito NN, Coppola D and Cheng JQ: MicroRNA-155 regulates cell survival, growth, and chemosensitivity by targeting FOXO3a in breast cancer. J Biol Chem 285: 17869-17879, 2010 . 
31. Song B, Wang C, Liu J, Wang X, Lv L, Wei L, Xie L, Zheng Y and Song X: MicroRNA-21 regulates breast cancer invasion partly by targeting tissue inhibitor of metalloproteinase 3 expression. J Exp Clin Cancer Res 29: 29, 2010.

32. Lee EJ, Baek M, Gusev Y, Brackett DJ, Nuovo GJ and Schmittgen TD: Systematic evaluation of microRNA processing patterns in tissues, cell lines, and tumors. RNA 14: 35-42, 2008.

33. Wu Z, Sun L, Wang H, Yao J, Jiang C, Xu W and Yang Z: MiR-328 expression is decreased in high-grade gliomas and is associated with worse survival in primary glioblastoma. PLoS One 7: e47270, 2012.

34. Shah MY, Pan X, Fix LN, Farwell MA and Zhang B 5-Fluorouracil drug alters the microRNA expression profiles in MCF-7 breast cancer cells. J Cell Physiol 226: 1868-1878, 2011.
35. Eiring AM, Harb JG, Neviani P, Garton C, Oaks JJ, Spizzo R, Liu S, Schwind S, Santhanam R, Hickey CJ, et al: miR-328 functions as an RNA decoy to modulate hnRNP E2 regulation of mRNA translation in leukemic blasts. Cell 140: 652-665, 2010.

36. Pan YZ, Morris ME and Yu AM: MicroRNA-328 negatively regulates the expression of breast cancer resistance protein (BCRP/ABCG2) in human cancer cells. Mol Pharmacol 75: 1374-1379, 2009.

37. Paduano F, Dattilo V, Narciso D, Bilotta A, Gaudio E, Menniti M, Agosti V, Palmieri C, Perrotti N, Fusco A, et al: Protein tyrosine phosphatase PTPRJ is negatively regulated by microRNA-328. FEBS J 280: 401-412, 2013 